\title{
Clinical variations of testicular intersexuality in a family
}

\author{
S. GARDÓ and Z. PAPP \\ Human Genetics Laboratory, University Medical School of Debrecen, H-4012 Debrecen, Hungary
}

Summary. A family, four members of which are affected by testicular intersexuality, is presented. Three of the four members suffer from testicular feminization, and one from pseudohermaphroditismus masculinus. Two patients with testicular feminization are half-sisters, the children of the same mother and two different fathers. This is a further proof of maternal transmission of the syndrome. Differences in the phenotypes of the patients belonging to one family may in all probability be explained by the differences in the expressivity of the pathological gene.

Several authors have given accounts in the literature of the accumulated incidence of the syndromes of testicular intersexuality within a family. It is well known that testicular feminization often occurs in the sibs of a family, and in the family of the mother of the affected patient (Hauser et al, 1957; Hamerton, 1971). A similar familial occurrence was observed in some forms in pseudo-hermaphroditismus masculinus (Reifenstein, 1947; GilbertDreyfus, Sébaoun, and Belaisch, 1957; Lubs, Vilar, and Bergenstal, 1959). According to the majority of authors the type of intersexuality within a family is reasonably constant, and only rarely do we read communications which report on different forms of intersex within a family (Barr et al, 1967).

In the family reported here the different forms of intersexuality affect four members of the family (Fig. 1). The proband's mother-whose sister (II.6) suffers from testicular feminization-married three times. Her first marriage resulted in a healthy boy (now deceased), while the only child originating from her second marriage was born with testicular feminization (III.2). Four children were born to the third marriage: a testicular feminization patient (III.3); a normal girl (III.5); a boy suffering from pseudohermaphroditismus masculinus (III.6); and a healthy boy (III.7).

\section{Case reports}

Case 1. (II.6) A female aged 50 years who never had any menses. For this reason and because of her ambiguous genital organs explorative laparotomy was carried out in 1940. In the course of the intra-abdominal examination it was established that the uterus and its appendages were missing, there was no prostate, the left testis was found to be in the canalis inguinalis. Although she felt psychosexually that she was female, she never

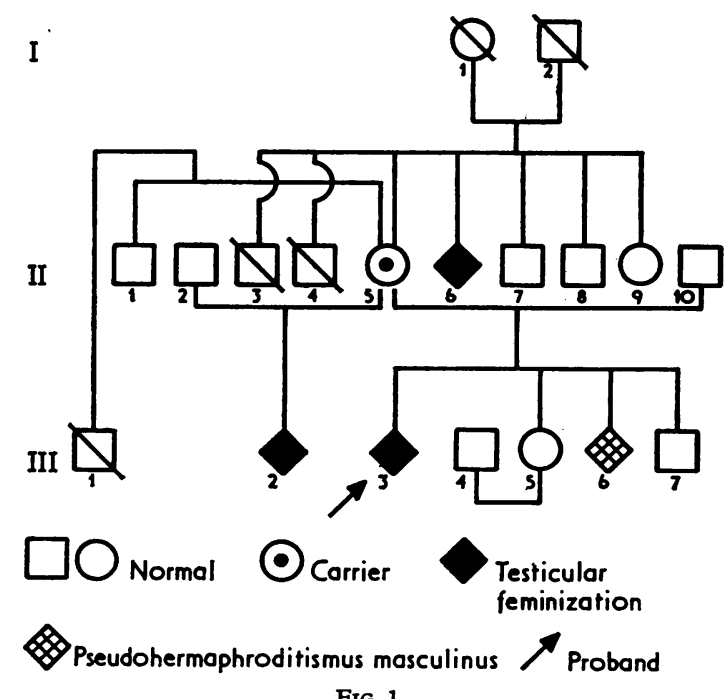

Received 9 November 1973. 
married, because she was conscious of the operative findings. When she lived a sexual life, her orgasm was normal.

Physical examination. She was $156 \mathrm{~cm}$ tall and weighed $60 \mathrm{~kg}$. Axillary hair is missing and pubic hair is sparse. Breasts are normal and correspond to her age. On the right side in the scrotum-like wrinkled pudendi labium majus a nut-sized testis can be palpated, the left testis is situated in the hernial duct (Fig. 2). The clitoris is $3 \mathrm{~cm}$ long and phallus-like, the vagina is $6 \mathrm{~cm}$ long and easily admits two fingers; there is also a blind pouch. The portio cannot be seen, the uterus cannot be palpated. Since the patient rejected a testis biopsy, we were not able to carry out histological examinations.

Cytogenetic examination. Sex-chromatin negative; 46,XY karyotype.

Case 2. (III.2) A 27-year-old female patient. She never menstruated, yet she lived for 4 years with a man and her sexual life-according to her-was balanced. She feels that she is unequivocally a woman, though in the past 2 years she has begun to grow a beard and her body hair has become more marked. Anamnesis reveals that because of her ambiguous external genital organs she underwent an explorative laparotomy in the course of which it was found that she had no uterus or ovaries.

Physical examination. Height is $163 \mathrm{~cm}$, weight is $58 \mathrm{~kg}$, she has an intersex physique. Axillary hair is sparse, pubic hair is dense but not of a virile character. There is an increased hair-growth on her abdomen and thighs. Her breasts are moderately developed. Testes of normal size can be palpated in the pudendum. The clitoris is $3 \mathrm{~cm}$ long, phallus-like, enlarged, and ending in a glans (Fig. 3). The vagina is 6 cm long, a blind pouch admitting two fingers, there is no palpable portio or uterus. The urethra opens into the vaginal stump $4 \mathrm{~cm}$ from the phallus. Medical and ophthalmological examination were negative. In view of the fact that there is an increasing virilization and that the testes in the pudendum disturbed the patient in the course of her sexual life, orchidectomy was carried out at her own request.

Histological examination. Testicular ducts comprised chiefly of Sertoli cells in association with fibre-rich interstitial substance and epididymis of histologically regular structure, with sporadic signs of spermatogenesis.

Cytogenetic examination. Sex-chromatin negative, fluorescing $\mathrm{Y}$ bodies were found in $60 \%$ of the examined oral mucosa by means of fluorescence technique. Her karyotype was $46, \mathrm{XY}$.

Case 3. (III.3) A 22-year-old female patient. She reported for examination on account of missed menstruation, otherwise she is free from any complaints.

Physical examination. She is $165 \mathrm{~cm}$ high and weighs $61 \mathrm{~kg}$, she has a gynecoid constitution. Axillary hair is missing, pubic hair is sparse, the breasts are well devel- oped and glandular to the touch. In the enlarged pudendum there are gonads of almost normal size, testislike to the touch, which can easily be pressed up into the inguinal canals. The labii minores are well developed and the clitoris is enlarged and is covered by a $3 \mathrm{~cm}$ long praepucium (Fig. 4). There is an apparently intact hymenal ring through which the patient can be examined with one finger. The vagina is contracted, $3 \mathrm{~cm}$ long, ending blindly; the portio and uterus are not palpable. Medical and ophthalmological examination were negative.

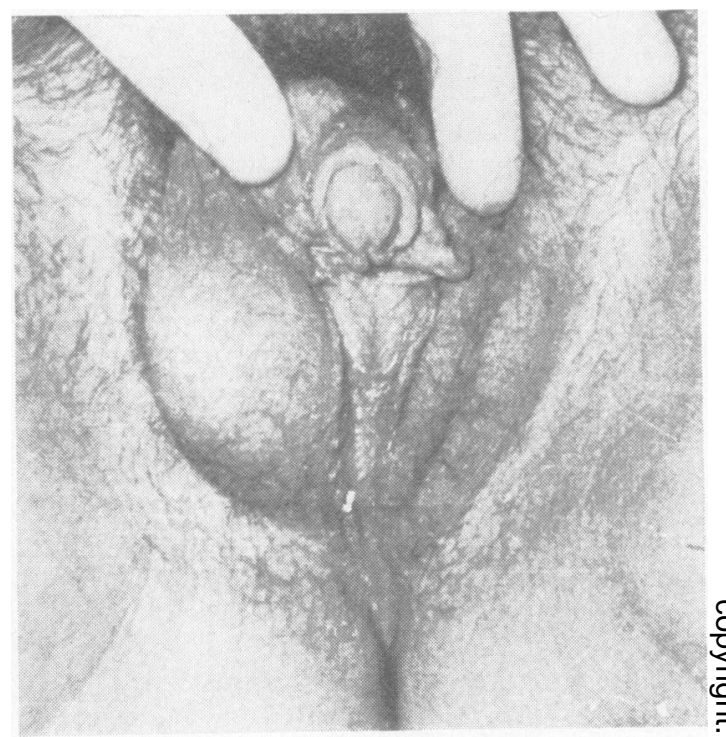

Fig. 2

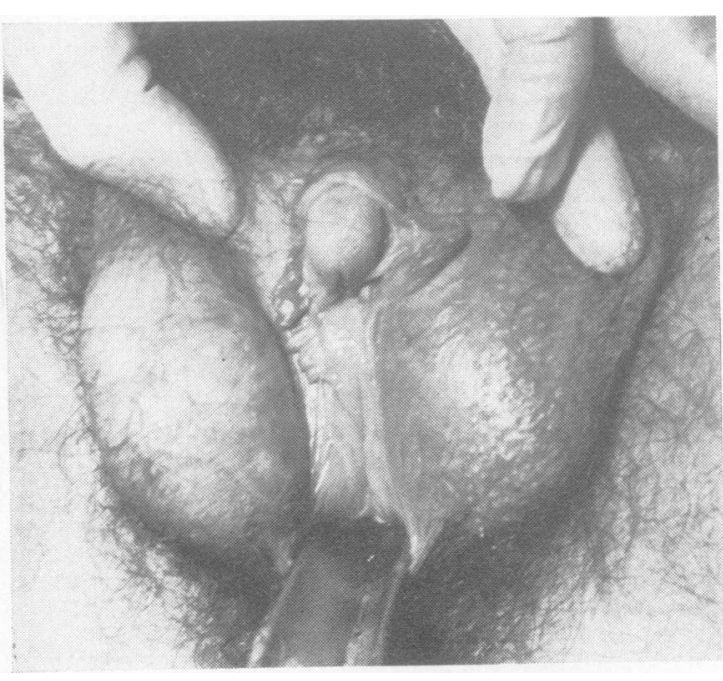

FIG. 3 


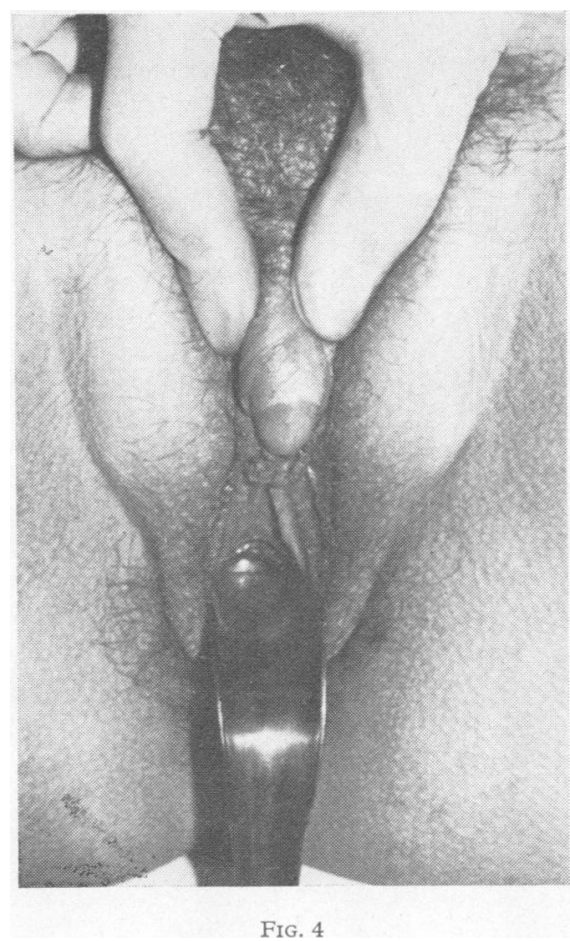

Exploratory laparotomy showed the pelvis minor to be, empty neither uterus nor tubes nor gonads could be seen.

Histological examination. A testis biopsy revealed an inactive testis with Sertoli cells and focal Leydig-cell hyperplasia in the interstices. No signs of spermatogenesis were observable.

Cytogenetic examination. Sex-chromatin were negative, karyotype was $46, \mathrm{XY}$.

Case 4. (III.6) An 18-year-old male. His personal anamnesis revealed that his breasts began to grow when he was 14 years of age.

Physical examination. $\mathrm{He}$ is $167 \mathrm{~cm}$ tall and weighs $64 \mathrm{~kg}$, he has an intersex constitution with moderately developed breasts glandular to the touch. The beard is floccular, the pubic hair is sparse. The rudimentary penis is hardly $3 \mathrm{~cm}$ long and ends in a glans. The urethra opens at the base of the phallus (perineoscrotalis hypospadiasis). The raphe is firmly pulled in, the scrotum is divided in two. Testes of normal size are palpable in the scrotum (Fig. 5). Medical and ophthalmological examination were negative. Exploratory laparotomy showed the pelvis minor to be empty, no tubes could be seen.

Histological examination. A testis biopsy revealed an inactive testis with Sertoli cells and focal Leydig-cell proliferation. There is no sign of spermatogenesis.

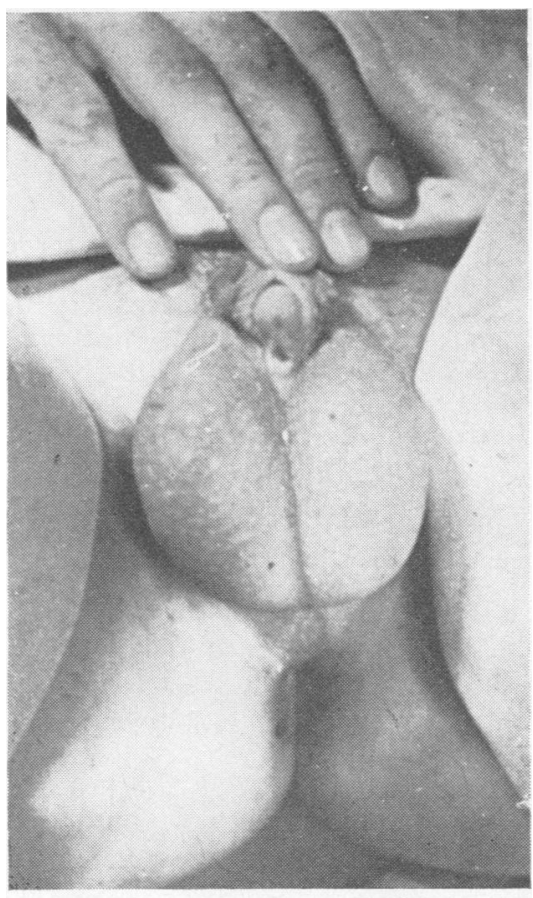

FIG. 5

Cytogenetic examination. Sex-chromatin were negative, karyotype was $46, \mathrm{XY}$.

\section{Discussion}

The analysis of the four patients described allows the following interesting conclusions to be drawn.

It has long been known that testicular feminization appears cumulatively in some families and occurs quite often in brothers and sisters. Either an autosomal dominant, or a recessive gene linked to an X-chromosome can be responsible for the inheritance of the syndrome. Recently Lyon and Hawkes (1970) demonstrated in mice that the Tfm gene is situated on the X-chromosome and this may indicate that it is the same in man.

The pathological gene is passed on to the offspring by the fact that the carrier state can often be verified in the mother of the affected individuals (belated menarche, sparse hair), and also because patients with testicular feminization can frequently be found in the mother's family, while the familial anamnesis of the father is negative in this respect. Cases 2 and 3 are half sisters and provide further proof of 
maternal inheritance. We have previously presented the first report of testicular feminization occurring in half-sisters (Gardó, Papp, and Arvay, 1971).

Our first three cases correspond clinically to the incomplete form of testicular feminization. Our fourth patient was registered as a boy, because the male characters dominated in his external genital organs. Though his constitution, his hair, the development of his breasts, and the situation of his gonads are in full agreement with those of his sister (case 3), yet he cannot be considered a case of testicular feminization as there is no sign of a vagina or female external genitals and his phallus is more reminiscent of a rudimentary penis than an enlarged clitoris. On the basis of these signs he can be classified as affected by pseudohermaphroditismus masculinus.

Significant differences can be observed in the phenotypes of three cases of testicular feminization. Case 3 is the most feminine, case 1 is also feminine, while case 2 has a virile build with weakly developed breasts. In contrast to this the vagina is the shortest in case 3 (only $3 \mathrm{~cm}$ ), while in the other two cases it is $6 \mathrm{~cm}$, suitable for married life. The situation of the gonads shows the greatest similarity, the testes can be found in the scrotumlike pudendum. Case 1 is exceptional, here the left testis is situated in the hernial canal. The shape and size of the phallus also shows great similarity in these three cases of testicular feminization.

Though the pathological signs of the four patients belonging to one family resemble one another in many respects, there are significant deviations in their phenotypes, which-taking into consideration the identical environment - can only be explained by the differences in the expressivity of the Tfm genes.

As already mentioned above, many authors have observed familial occurrences similar to testicular feminization in some forms of pseudohermaphroditismus masculinus. For instance, Cohen and Shaw (1965) have described the XY-type of pure gonadal dysgenesis in brothers and sisters, Sternberg, Barclay, and Kloepfer (1968) in cousins, and Frasier, Bashore, and Mosier (1964) in twins. Espiner et al (1970) gave an account of a family in which five phenotypically female members were affected. This form of gonadal dysgenesis is inherited in a manner similar to that of testicular feminization, that is by means of an autosomal dominant or a recessive sex-linked gene. It may therefore be established that testicular feminiza- tion, pseudohermaphroditismus masculinus, and the XY-type of pure gonadal dysgenesis are inherited in a similar manner.

In the present family the incomplete form of testicular feminization and the pseudohermaphroditismus masculinus occurs in sibs. Barr et al (1967) on the other hand reported pseudohermaphroditismus masculinus and XY-type pure gonadal dysgenesis in two sisters.

Our cases also seem to support those earlier suppositions that an identical gene may play a role in bringing about some cases of pseudohermaphroditismus masculinus, testicular feminization, and the XY-type of pure gonadal dysgenesis, and that the difference in the expressivity of the gene may explain the different phenotypes (Federman, 1967; Hamerton, 1971). In this respect the testicular feminization is a link in the row of testicular intersexes. The incomplete forms associated with clitoris hypertrophy form a transition through pseudohermaphroditismus masculinus to the normal male.

\section{REFBRBNCBS}

Barr, M. L., Carr, D. H., Plunkett, E. R., Soltan, H. C., and Wiens, R. G. (1967). Male pseudohermaphroditism and pure gonadal dysgenesis in sisters. American fournal of Obstetrics and Gynecology, 99, 1047-1055.

Cohen, M. M. and Shaw, M. W. (1965). Two XY siblings with gonadal dysgenesis and female phenotype. New England fournal of Medicine, 272, 1083-1088.

Espiner, E. A., Veale, A. M. O., Sands, V. E., and Fitzgerald, P. H. (1970). Familial syndrome of streak gonads and normal male karyotype in five phenotypic females. New England fournal of Medicine, 283, 6-11.

Federman, D. D. (1967). Abnormal Sexual Development. Saunders, London and Philadelphia.

Frasier, S. D., Bashore, R. A., and Mosier, H. D. (1964). Gonadoblastoma associated with pure gonadal dysgenesis in monozygous twins. Fournal of Pediatrics, 64, 740-745.

Gardó, S., Papp, Z., and Arvay, A. (1971). Incomplete testicular feminization in 'half-sisters'. Acta Medica Auxologica, 3, 3-7.

Gilbert-Dreyfus, S., Sébaoun, C. A., and Belaisch, J. (1957). Étude d'un cas familial d'androgynoïdisme avec hypospadiasis grave, gynécomastie et hyperoestrogénie. Annales d'Endocrinologie, 18, 93-101.

Hamerton, J. L. (1971). Human Cytogenetics, vol. 2. Academic Press, London and New York.

Hauser, G. A., von Keller, M., Koller, T., Wenner, R., and Gloor, F. (1957). "Testikuläre Feminisierung" bei Erwachsenen. Schweizerische Medizinische Wochenschrift, 87, 1573-1580.

Lubs, H. A. Vilar, O., and Bergenstal, D. M. (1959). Familial male pseudohermaphroditism with labial testes and partial feminization: endocrine studies and genetic aspects. Fournal of Clinical Endocrinology and Metabolism, 19, 1110-1120.

Lyon, M. F. and Hawkes, S. G. (1970). X-linked gene for testicular feminization in the mouse. Nature, 227, 1217-1219.

Reifenstein, E. C. (1947). Hereditary familial hypogonadism. Proceedings of the American Federation for Clinical Research, 3, 86-89.

Sternberg, W. H., Barclay, D. L., and Kloepfer, H. W. (1968). Familial XY gonadal dysgenesis. New England fournal of Medicine, 278, 695-700. 